\title{
Congenital diaphragmatic hernia: current status and review of the literature
}

\author{
Anthony S. de Buys Roessingh • Anh Tuan Dinh-Xuan
}

Received: 4 September 2008 / Accepted: 6 December 2008 / Published online: 23 December 2008

(C) Springer-Verlag 2008

\begin{abstract}
Treatment of congenital diaphragmatic hernia $(\mathrm{CDH})$ challenges obstetricians, pediatric surgeons, and neonatologists. Persistent pulmonary hypertension (PPHT) associated with lung hypoplasia in $\mathrm{CDH}$ leads to a high mortality rate at birth. PPHT is principally due to an increased muscularization of the arterioles. Management of $\mathrm{CDH}$ has been greatly improved by the introduction of prenatal surgical intervention with tracheal obstruction (TO) and by more appropriate postnatal care. TO appears to accelerate fetal lung growth and to increase the number of capillary vessels and alveoli. Improvement of postnatal care over the last years is mainly due to the avoidance of lung injury by applying low peak inflation pressure during ventilation. The benefits of other drugs or technical improvements such as the use of inhaled nitric oxide or extracorporeal membrane oxygenation (ECMO) are still being debated and no single strategy is accepted worldwide. Despite intensive clinical and experimental research, the treatment of newborn with $\mathrm{CDH}$ remains difficult.
\end{abstract}

Keywords Diaphragmatic hernia P Pulmonary hypertension $\cdot$ Tracheal obstruction $\cdot$ Postnatal care

A. S. de Buys Roessingh ( $\square)$

Service de Chirurgie Pédiatrique,

Centre Hospitalier Universitaire Vaudois,

Rue du Bugnon 46,

1011 Lausanne, Switzerland

e-mail: anthony.debuys-roessingh@Chuv.ch

A. T. Dinh-Xuan

Faculté de Médecine, EA 2511, Assistance Publique Hôpitaux

de Paris, Service de Physiologie-Explorations Fonctionnelles.

Hôpital Cochin, Université Paris Descartes,

27 rue du faubourg Saint-Jacques,

75679 Paris cedex 14, France

\begin{tabular}{|c|c|}
\hline \multicolumn{2}{|c|}{ Abbreviations } \\
\hline $\mathrm{CDH}$ & congenital diaphragmatic hernia \\
\hline PPHT & persistent pulmonary hypertension \\
\hline TO & tracheal obstruction \\
\hline ECMO & extracorporeal membrane oxygenation \\
\hline $\mathrm{NO}$ & nitric oxide \\
\hline $\mathrm{HFO}$ & high-frequency oscillation \\
\hline PVR & pulmonary vascular resistance \\
\hline US & ultrasound \\
\hline LHR & lung-heart-ratio \\
\hline MRI & magnetic resonance imaging \\
\hline FETO & fetal tracheal occlusion \\
\hline VEGF-A & vascular endothelial growth factor-A \\
\hline PDGF-B & platelet-derived growth factor-B \\
\hline IGF-II & insulin-like growth factor-II \\
\hline MAPK & mitogen-activated protein kinase \\
\hline ET-1 & endothelin-1 \\
\hline FETENDO & fetal endoscopic surgery \\
\hline EXIT & ex utero intrapartum treatment \\
\hline iPPROM & $\begin{array}{l}\text { iatrogenic preterm rupture of the fetal } \\
\text { membrane }\end{array}$ \\
\hline $\mathrm{PaCO}_{2}$ & arterial pressure of $\mathrm{CO}_{2}$ \\
\hline $\mathrm{GC}$ & guanylate cyclase \\
\hline PDE V & cGMP-specific phosphodiesterase \\
\hline $\mathrm{TXA}_{2}$ & thromboxane $\mathrm{A}_{2}$ \\
\hline $\mathrm{PGI}_{2}$ & prostacyclin \\
\hline $\mathrm{COX}$ & cyclooxygenase enzyme \\
\hline $\mathrm{AC}$ & adenylate cyclase \\
\hline cGMP & cyclic $3{ }^{\prime}-5^{\prime}$-guanylosine monophosphate \\
\hline PKG & cGMP dependent proteine kinase \\
\hline $\mathrm{K}_{\mathrm{ca}}{ }^{2+}$ & $\mathrm{K}^{+}$channels calcium dependant \\
\hline iGMP & inactive $3^{\prime}-5^{\prime}$-guanylosine monophosphate \\
\hline YC-1 & A benzyl indazole derivative \\
\hline $\mathrm{AadO}_{2}$ & alveolar-arterial oxygen gradient \\
\hline VI & ventilatory index \\
\hline
\end{tabular}




$\begin{array}{ll}\text { RR } & \text { respiratory rate } \\ \text { MAP } & \text { median arterial pressure } \\ \text { MVI } & \text { modified ventilatory index } \\ \text { PIP } & \text { peak inspiratory pressure } \\ \mathrm{OI} & \text { oxygenation index } \\ \mathrm{FiO}_{2} & \text { inspiratory fraction of oxygen } \\ \mathrm{PaO}_{2} & \text { arterial pressure of } \mathrm{O}_{2} \\ \text { GER } & \text { gastroesophageal reflux }\end{array}$

\section{Introduction}

Congenital diaphragmatic hernia (CDH) combines a muscle defect between the abdomen and the thoracic cavity with pulmonary hypoplasia. The muscle defect leads to a herniation of the abdominal viscera into the thoracic cavity $[12,44]$. It usually stems from the left posterolateral part of the muscle and is called Bochdalek hernia [55]. The Morgagni hernia concerns the antero-medial retrosternal portion of the diaphragm and the esophageal hiatal hernia arises from a physiological orifice. Riverius was the first to describe a $\mathrm{CDH}$ in 1679, Morgagni described different types of diaphragmatic hernia in 1761, and in the nineteenth century Victor Bochdalek described his autopsies of children with $\mathrm{CDH}$.

$\mathrm{CDH}$ occurs in $1 / 2,500$ to $1 / 5,000$ live births. No specific causal gene defects have been identified in humans and most cases are sporadic. A few drugs such as pyridoxine, thalidomide, quinine, and antiepileptic drugs have been implicated in the occurrence of $\mathrm{CDH}$. However, its true incidence is probably higher because some fetuses with severe $\mathrm{CDH}$ die in utero and are spontaneously aborted. Eighty-four percent of $\mathrm{CDH}$ are left-sided, 14\% right-sided, and $2 \%$ bilateral $[58,104]$. $\mathrm{CDH}$ is often associated with cardiac, gastrointestinal, genitourinary, skeletal or neural anomalies and with trisomies [48, 58]. The incidence of associated anomalies in infants born with a $\mathrm{CDH}$ ranges from $10 \%$ to $40 \%$ [27]. In about $30 \%$ of cases, these malformations appear as skeletal defects such as limb reduction or costovertebral defects [97]. Cardiac malformations such as hypoplasia of the aortic arch, tetralogy of Fallot, transposition of the great vessels or aortic coarctation occur in about $25 \%$ of cases [96]. Congenital tracheal stenosis, tracheal bronchus or other tracheal malformations can also be found in association with $\mathrm{CDH}$ [74]. Neural tube defects seem to be the most common findings in infants with $\mathrm{CDH}$ who died in utero [96].

$\mathrm{CDH}$ alone has a mortality rate of $20 \%$ and the degree of associated pulmonary hypoplasia and the severity of pulmonary hypertension remain the major determinant of survival [89]. When the associated anomalies are severe, the mortality rate can be as high as $90 \%$ [58]. Stege et al.
[90] showed that the two factors which clearly influence postnatal mortality are the timing of the termination of gestation and the presence of additional anomalies. They showed that the survival rate of infants diagnosed with $\mathrm{CDH}$ has not improved in the past 10 years despite new therapies, and that half of the cases had not been detected by antenatal scanning, leading to the birth of infants with a life-threatening condition in an unprepared obstetric unit. They also noted that $\mathrm{CDH}$ had remained undiagnosed in some infants who had died immediately after birth [90]. Therefore, the overall mortality of children with a CDH is difficult to determine.

Long-term compression of fetal lungs by the herniation of the viscera into the thoracic cavity results in pulmonary underdevelopment and lung hypoplasia [3, 36, 55]. This was confirmed in both ipsilateral and contralateral pulmonary specimens by an analysis of lung volumes and weights during autopsies of humans and of animal models [76]. Structural alterations in CDH lungs are a decrease of the total arteriolar cross-sectional area and a significant adventitial and medial wall thickening in pulmonary arteries of all sizes, with abnormal muscularization of the small pre-acinar and intra-acinar arterioles, leading to a persistent pulmonary hypertension (PPHT) which causes the death of babies before or after birth $[18,67]$. The probability of survival in children born with $\mathrm{CDH}$ is therefore determined mainly by the severity of lung hypoplasia and the presence of PPHT causing abnormal pulmonary compliance, refractory respiratory failure at birth, hypoxemia, right to left extrapulmonary shunting of blood, progressive acidosis (Fig. 1) and heart failure [51, 68].

Even fetuses which survive up to delivery have significant lung hypoplasia and impaired lung function which lead to long-term morbidity. Since the 1980 s, there have been many advances in the care of neonates, in particular the introduction of drugs such as the surfactant, and later the discovery by Furchgott and Zawadzki [32] of nitric oxide (NO), which can reduce PPHT in most pathologies. Other advances were the use of high-frequency



Fig. 1 Physiopathology of the persistent pulmonary hypertension (PPHT) in $\mathrm{CDH}$ 
oscillation (HFO) and extracorporeal membrane oxygenation (ECMO). Although all these advances have proved efficient in most diseases related to PPHT, treatment of $\mathrm{CDH}$ remains difficult and challenging as no single treatment has yet proved to be very efficient [100]. Surgery "in utero", with the insertion of a temporary tracheal occlusion (TO) to improve lung growth and lung capacity, is a new approach in the treatment of children with $\mathrm{CDH}$ but its indication in cases of fetuses with severe lung hypoplasia is still debated.

Anomalies of pulmonary vascularity [117], such as hyperplasia of the smooth muscle cells play a decisive role in maintaining a high pulmonary vascular resistance (PVR), pulmonary vascular compliance and therefore blood flow [34]. The smaller arteries, those with an external diameter of less than $200 \mu \mathrm{m}$, are predominantly responsible for PVR [99]. To be more precise, pulmonary vascular abnormalities in $\mathrm{CDH}$ consist in a decreased number of pulmonary arteries per unit of lung volume and in the peripheral muscularization of small arteries, with medial and adventitial thickening [85, 117]. Increased adventitial and medial thickness of the pulmonary arterial wall is the most striking structural changes which have been reported in patients with CDH complicated by PPHT [34]. The presence of abnormally thick-walled pulmonary arteries in newborn with $\mathrm{CDH}$ suggests that their intrapulmonary arteries may become excessively muscularized during fetal life and unable to adapt normally at birth. In fetuses, studies of blood flow with a 3-D Doppler showed decreased vascularity, decreased pulmonary blood flow, and decreased pulmonary blood flow per volume of blood vessels [80].

\section{Management}

There is to this day no consensus on the treatment of babies with PPHT. Studies on the treatment of these children have to be interpreted carefully for different reasons: firstly, comparisons of the degree of herniation are difficult, and the criteria applied to determine whether a $\mathrm{CDH}$ is moderate or severe are not always the same and may bias the appraisal of patients and affect the decision on the mode and timing of the treatment; secondly, no criteria for the selection of a particular treatment have been validated in large series, and the choice of treatment depends largely on the strong belief of the team-leader; and thirdly, the survival rate is higher in large centers, where a great number of children are born or transferred every year, than in smaller centers where these cases are few and far between [47].

The evaluation of a fetus suspected of presenting $\mathrm{CDH}$ includes a prenatal high-resolution ultrasound (US) exam- ination to confirm the diagnosis. Between $40 \%$ and $60 \%$ of infants with $\mathrm{CDH}$ are diagnosed prenatally [33]. Normally, the first sign evidenced by US is the presence of fluid-filled loops of bowel in the thorax. The small bowel and the stomach are both involved in $90 \%$ of cases. A bad prognosis can be presaged before birth on the basis of different signs and measurements provided by US: an early diagnosis at 24 weeks of gestation with a large muscular defect, a dilated intrathoracic stomach, a herniated left lobe of the liver and the presence of a polyhydramnios are predictive of severe pulmonary hypertension at birth and of a poor outcome [94]. Subsequent US examinations are performed to assess the contents of the hernia, evaluate any associated malformations and measure the lung-heart ratio (LHR). It is important to know the position of the liver because the prognosis for a baby with a herniated liver is not good. A US-Doppler examination can be done to check the position of the umbilical vein and of the hepatic vessels. Various indexes have been proposed to evaluate the prognosis after a US examination. In 2000, Suda [94] showed that the most significant prognostic factor was the modified McGoon index, which is the diameter of the proximal pulmonary artery indexed to the descending aorta. An index of 1.3 or less predicts mortality with a sensitivity of $85 \%$ and a specificity of $100 \%$.

Magnetic resonance imaging (MRI) realized prenatally can be of importance to resolve a doubt about the position of the liver, to evaluate the volume of the lungs or to distinguish a $\mathrm{CDH}$ from other malformations such as a cystic adenomatoid malformation, pulmonary sequestration, bronchogenic cyst, enteric cysts or mediastinal teratoma. This technique is an excellent mode of imaging when an exquisite anatomical detail has to be discussed precisely. Karyotyping is also mandatory as $\mathrm{CDH}$ is frequently associated with chromosomal anomalies.

Several choices can be envisioned and proposed to the parents of a child with a $\mathrm{CDH}$ diagnosed prenatally and a bad prognosis: interrupt the pregnancy (before 24 weeks), let the pregnancy follow its course up to delivery, or consider prenatal surgery and TO. As $\mathrm{CDH}$ has a significant mortality rate, there is a hope that an intervention in utero may improve the outcome for the child.

\section{Prenatal management}

A multidisciplinary team includes at least neonatalogists, obstetricians, pediatric surgeons, geneticists, and cardiologists. Fetal surgery is normally shared by pediatric surgeons and obstetricians but the management of each case and the decision to perform surgery must be the result of a multidisciplinary discussion which takes into account the context of the malformation, the various signs indicative of 
its gravity, the gestational age at diagnosis, and the family's history and likelihood to consent to the procedure [14].

In 1990, Harrison et al. in San Francisco were the first to operate in utero on children with $\mathrm{CDH}$ [38]. This new surgical approach encountered difficulties, and its results were not always completely successful. There was a high rate of preterm deliveries due to infection and difficulties in maintaining tocolysis. The reduction of a liver herniated into the thorax proved difficult and provoked an obstruction of the umbilical blood flow and the death of the fetus [39].

Tremendous advances were made following the observation that the prevention of a normal efflux of intraluminal lung liquid has a positive influence on lung growth by stimulating the development of pulmonary parenchyma [114]. This finding led to the concept that occluding the trachea before birth (Fetal Tracheal Occlusion or FETO) could enhance lung growth and improve the outcome after birth [21, 30, 40, 41].

Animals with $\mathrm{CDH}$ treated by tracheal occlusion developed lungs whose appearance and function were normal, and their rate of survival was significantly improved in comparison to control animals [23]. In sheep and rats with a nitrofen-induced $\mathrm{CDH}[54,63]$, tracheal occlusion results in lung growth, and morphometric studies show a decrease in the thickening of the small pulmonary arteries [50, 54].

Attempts were made to explain the mechanism of lung adaptation after FETO by searching for the presence of such molecules as vascular endothelial growth factor-A (VEGF-A), platelet-derived growth factor-B (PDGF-B), insulin-like growth factor-II (IGF-II), mitogen-activated protein kinase (MAPK) or endothelin-1 (ET-1) [11, 37, 111].

\section{Indication and measurements}

Fetal surgery is a treatment which is available only in the few centers which receive a sufficient number of cases [47]. While counseling on the possibility of fetal surgery and the organization of the delivery is normally provided by a team of neonatologists, gynecologists, geneticians, and pediatric surgeons, fetal surgery itself relies also on the expertise of other teams such as radiologists and on the availability of special instrumentation, and its complexity precludes its widespread application and limits its execution to a few highly specialized fetal treatment centers.

Although a variety of indexes have been suggested, there are as yet no real markers to determine the gravity of the pulmonary hypertension which will be found at birth. The capability of identifying high-risk fetuses in the prenatal period is crucial in order to select those fetuses which will benefit from prenatal high-risk interventions. Actually, two criteria are taken into consideration in the selection of highrisk fetuses:

- The position of the liver. Fetuses whose liver is partially herniated into the thoracic cavity have a $50 \%$ chance of survival $[19,80]$.

- The ratio between lung and head (Fig. 2), called LHR $[59,60,84]$. Group A: A LHR lower than 0.6 points to a very poor outcome for the fetus, with extreme lung hypoplasia and a mortality rate of almost $100 \%$. Group B: a ratio between 0.6 and 1 gives the fetus which has a severe lung hypoplasia a predictive survival rate of 15 to $60 \%$. FETO is normally proposed for these babies. Group C: a ratio in the range of 1.0 to 1.6 gives the child a $66 \%$ chance of survival and a predictive survival rate of more than $83 \%[60,84]$. However, even for these babies, the indication of FETO is under discussion as the beneficial effect of FETO has not yet been proved. In a prospective series in 1997, Lipshutz [60] showed that no fetus having a LHR of less than 1 survived to a postnatal age of 60 days, and that only children with a LHR greater than 1.4 could survive. But it has also been demonstrated that LHR is not a predictive factor in fetuses with a left $\mathrm{CDH}$ and a normal position of the liver [84].

On the basis of these two criteria, the FETO procedure, with the PLUG being inserted between 26 and 28 weeks of gestation, and the UNPLUG performed at 34 weeks of gestation, is proposed for fetuses showing (1) a LHR of less

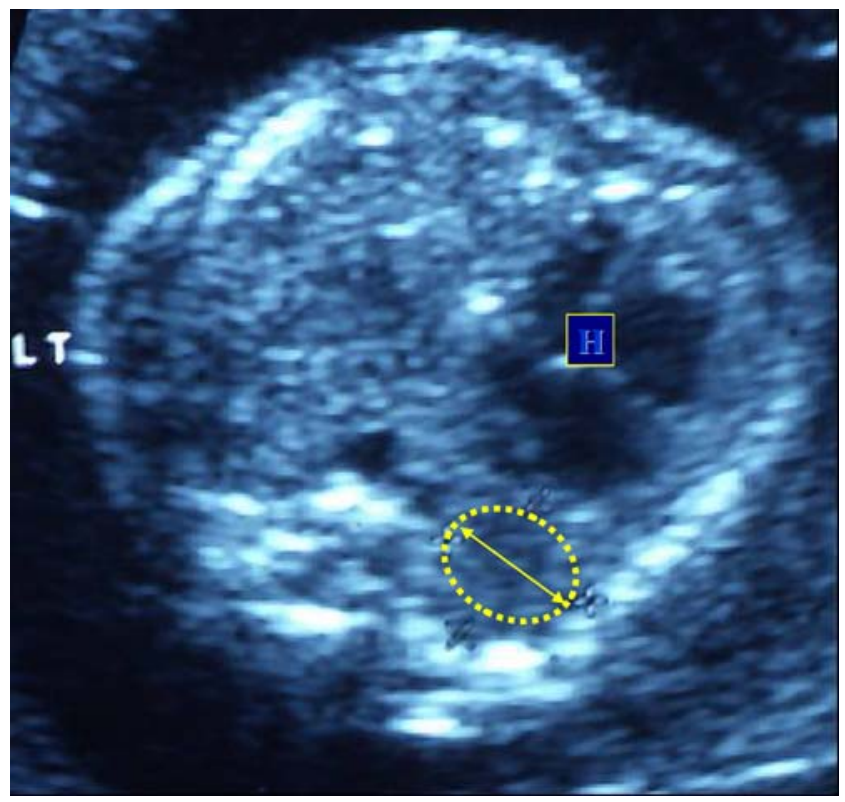

Fig. 2 Example of lung-to-head ratio (LHR) measured during ultrasonography. $H$ heart; arrow pulmonary diameter. A LHR lower than 0.6 points to a very poor outcome for the fetus, a ratio between 0.6 and 1 gives the fetus a better predictive survival rate of 15 to $60 \%$ 
than $1,(2)$ a herniation of a large portion of the liver including part of the left lobe, (3) a normal genetic karyotype, (4) no associated abnormalities and (5) a singleton pregnancy at 25 weeks of gestation. One must also make sure that the anesthesia and surgery will not put the mother at risk. The timing and duration of the occlusion are the subjects of discussion and research as they are crucial to the beneficial effect of the procedure, i.e., increased pulmonary stretch and accelerated growth of airways and pulmonary vessels.

\section{Surgery}

After routine preoperative laboratory studies and a physical examination, an ultrasound examination is carried out to check the viability of the fetus. Indomethacin is given in the morning to provide uterine relaxation. An epidural block is placed to allay the pain of the mother and the fetus. Compression stockings are used as a precaution against thromboembolic risks. Anesthesia is realized with isoflurane inhalation to ensure uterine relaxation. The patient is draped for surgery.

Two important advances in this prenatal surgery have been developed: the first advance is the development of the technique which allows the procedure to be performed fetoscopically, whereby a balloon is inserted percutaneously through a $3.3 \mathrm{~mm}$ incision to create the endoluminal tracheal occlusion at 26-28 weeks of gestation. Previously, surgery in utero entailed a hysterotomy: the maternal abdomen was opened by a low transverse laparotomy, a hysterotomy was performed under ultrasound control. A pulse oximetry device was applied to the hand and the throat was exposed for a midline neck dissection in order to isolate the trachea. The trachea was occluded by two hemoclips facing each other. Closure was then executed layer by layer. Continuous patient-controlled epidural analgesia was provided for the relief of maternal postoperative pain. Tocolysis was ensured by intravenous doses of magnesium sulfate and indomethacin and continued to the end of the pregnancy. Bed rest was normally prescribed for the mother, who was monitored for signs and symptoms of preterm labor. Follow-up ultrasound examinations were performed to measure lung parenchyma and check on the expected gradual increase in lung volume. But the rate of survival of the fetuses was low and the morbidity of survivors not acceptable [39]. Then, in 2000, it was reported that fetoscopic endoluminal tracheal occlusions had been performed on lamb fetuses [77] with endoscopic instruments. This type of surgery, called FETENDO for "fetal endoscopic surgery", was later also performed on human fetuses [21, 40, 41].

The second advance was the improvement in the material used for tracheal occlusions. The placement below the vocal cords of a water impermeable and expandable polymeric foam in a gelatin capsule, introduced into the trachea by means of a fetoscope with a detachable balloon occlusion system, appears to be well tolerated by the fetus and to stimulate excellent lung growth without causing tracheal damage [20]. The fetoscope has a diameter of $1.2 \mathrm{~mm}$, in a sheath whose diameter measures $3 \mathrm{~mm}$. This method represents a marked advance on the fetoscopic fetal occlusion with clips, which can give rise to numerous surgical complications [41].

The restoration of airway potency by removal of the balloon can be realized prior to birth at 34 weeks of gestation, or by "Ex utero Intrapartum Treatment (EXIT)" during delivery. The first method avoids the drawback of a long-term tracheal occlusion which provokes the differentiation of type II pneumocytes into type I pneumocytes with surfactant deficiency. The procedure is performed prior to birth, at 34 weeks of gestation, either by fetal tracheoscopy, by ultrasound-guided puncture of the balloon using a fetoscope, or by deflation of an expandable balloon [20]. It is carried out under locoregional anesthesia or epidural anesthesia, with prophylactic tocolysis for the mother and fentanyl and pancuronium for the fetus [8]. The risk entailed by this procedure is the "iatrogenic preterm rupture of the fetal membrane" or iPPROM $[8,20]$.

The second method, EXIT, is a procedure which allows the retrieval of the balloon by tracheoscopy during birth. It can only be performed in institutions which have the appropriate equipment [8]. Labor is induced shortly before term and a laparotomy and a hysterotomy are performed under deep anesthesia to effect uterine relaxation and a good uterine perfusion. The neck of the baby is quickly exposed to allow the removal of the balloon or of the tracheal clips and to do a bronchoscopy. The baby is then intubated and given surfactant. Once it is stabilized in the neonatal intensive care unit, $\mathrm{CDH}$ repair is performed.

There is no proof that the outcome is more favorable for children who had a PLUG installed in utero, and a randomized trial was terminated early after showing that they fared no better than children who had not had a PLUG but had been delivered in specialized centers [19, 20]. Nevertheless, further attempts were made on fetuses with a very low prognosis following precise measurements in utero [41]. In 2006, Deprest [19] reported a 75\% neonatal survival rate, with $90 \%$ patch repair in $66 \%$ of operated children, and a $58 \%$ neonatal survival rate in 24 consecutive cases of $\mathrm{CDH}$ where the mean duration of tracheal occlusion had been 42 days. Although preliminary results of FETO surgery are encouraging, there is as yet no statistical proof that fetal surgery offers better results than postnatal management in terms of survival and long-term morbidity. A randomized study in at least one center should 
therefore be carried out before FETO surgery becomes widespread.

\section{Postnatal treatment}

At birth, babies with $\mathrm{CDH}$ will have a flat abdomen, bowel sounds in the chest, cardiac sounds shifted laterally, and breathing difficulties. All efforts should be made to stabilize the cardiopulmonary system during resuscitation with a minimum of iatrogenic injuries. When the $\mathrm{CDH}$ is severe, the babies are normally intubated to relieve respiratory distress, and a gastric tube is inserted to decompress the stomach. Ventilation by mask is contraindicated as it may cause a distention of the stomach situated in the thoracic cavity. Arterial and venous access should be acquired through the umbilical vessels in order to obtain blood gas samples and to monitor central venous pressure. Adequate oxygen delivery must be given, with proper temperature regulation and glucose homeostasis. The children must be sedated but muscle paralysis is not encouraged because of its untoward consequences on ventilatory mechanics. Systemic hypotension must be reversed with fluid administration. A chest radiography will usually show gas-filled loops of bowel in the chest along with a shift of the heart to the other side of the defect (Fig. 3). When the CDH is mild, symptoms may not be immediately manifest and can appear only after several months [25].

Advances in neonatal reanimation have greatly improved the outcome of babies born with $\mathrm{CDH}$. The introduction of different types of ventilation, the use of $\mathrm{NO}$ and the use of extracorporeal membrane oxygenation (ECMO) are responsible for this improvement. Nevertheless, the benefits of

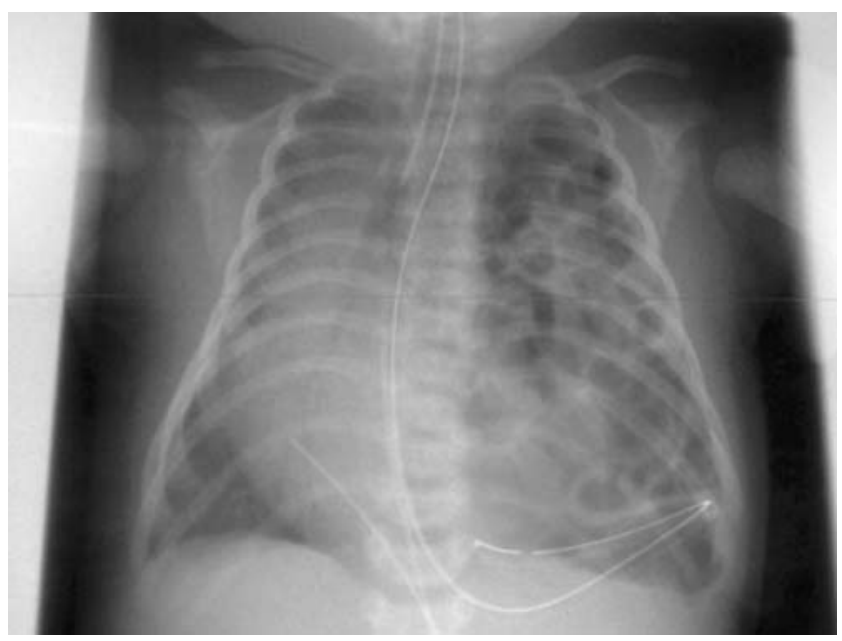

Fig. 3 At birth, a chest radiography will usually show gas-filled loops of bowel in the chest (left side on this radiograph) along with a shift of the heart to the other side of the defect (right side on this radiograph) these various techniques and drugs are still being debated and there is as yet no general agreement on the application of one or the other. Even if these techniques taken individually have not proved truly beneficial to babies born with a $\mathrm{CDH}$, their conjunction, or at times their alternance, is beneficial. But more long-term follow-up data on the results of these treatments is needed to assess the mortality and morbidity of children born with a severe CDH. An additional problem is the fact that a truly valid comparison of treatment results can only be made if the children treated present an equal degree of gravity of their $\mathrm{CDH}$.

\section{Conventional ventilation}

The optimal mode of ventilation for children with $\mathrm{CDH}$ at birth is not defined. Conventional ventilation is based on "gentle" ventilation to avoid any barotrauma which could add another pulmonary problem to the existing pulmonary hypertension. The principle of "gentle" ventilation is based on controlling the peak inflation pressure (18 to $22 \mathrm{cmH}_{2} \mathrm{O}$ ) by limiting the pressure of ventilation while tolerating an oxygen saturation of $85 \%$ and a rise of the arterial pressure of $\mathrm{CO}_{2}\left(\mathrm{PaCO}_{2}\right.$; permissive hypercapnia), and stimulating spontaneous ventilation $[1,61,83,116]$. Boix-Ochoa was the first to report that differences in pre- and postductal $\mathrm{pH}$ and $\mathrm{PaCO}_{2}$ could be used to differentiate survivors and non survivors, thereby demonstrating the influence of the $\mathrm{pH}$ and the $\mathrm{PaCO}_{2}$ on pulmonary vascular tone and ductal shunting [7]. Transporters of gas such as perfluorocarbons can be used as a medium for liquid ventilation. Due to their weak solubility in lipids, they reduce the surface tension of the alveoli and allow a lower pressure of ventilation. Perfluorocarbons can also be used for the local administration of anesthetics and vasodilators [115].

Barotrauma is an additional and leading cause of morbidity and mortality in children with CDH [110]. Studies have demonstrated that increased mortality in children with $\mathrm{CDH}$ was due to a high ventilatory rate and a high inspiratory pressure [87]. The mechanisms of ventilator-induced pulmonary damage involve a structural disruption due to lung overdistension and shear-stress forces generated by the repetitive opening and collapse of the atelectatic regions of the lung. These mechanisms induce a capillary leak in the endothelium and epithelium, a rupture of the basement membrane, a leakage of fluid in the alvealor spaces, a general inflammatory response and an impairment of the secretion of surfactant [110].

High-frequency oscillation (HFO)

HFO was introduced in the 1980s in an attempt to ameliorate gas exchange in the lung by avoiding the high inspiratory pressure produced by conventional ventilation 
and keeping a mean airway pressure of about $15 \mathrm{cmH}_{2} \mathrm{O}$ and an amplitude of less than $45 \mathrm{mmHg}[6,57]$. HFO can used as the first choice of ventilation for babies born with $\mathrm{CDH}$ or when conventional ventilatory strategies fail. There is actually no proof that HFO is better than conventional ventilation [5] but the low-tidal-volume regimen induced by HFO may be less deleterious to the lungs than a high-tidalvolume ventilation [9]. The choice of different modes of ventilation depends largely on the convictions of different teams, who quite try alternate strategies of ventilation when pulmonary hypertension due to $\mathrm{CDH}$ does not respond to a first treatment. The teams who chose HFO as a ventilatory strategy reported good results even in children with a bad prognosis [22].

\section{Surfactant}

Suen et al. [95] have shown that lung immaturity in babies with $\mathrm{CDH}$ can lead to a deficiency of disaturated phosphatidylcholine and a deficiency of surfactant [113]. These findings have not been confirmed by other groups [119]. Most studies on the lack of surfactant were carried out mainly on animal models such as rats, where the production of surfactant seems to be ameliorated by the administration of vitamin A [101, 103].

Even though the use of exogenous surfactant in children with $\mathrm{CDH}$ has not been studied in a controlled clinical trial, it constitutes a standard treatment in the fight against PPHT in children with $\mathrm{CDH}$, especially in conjunction with other treatments. It has been proved in animal models (rats and lambs) that lungs with $\mathrm{CDH}$ are deficient in surfactant [35]. There is little data on the deficiency of surfactant in human lungs at birth $[62,66,70]$. Recent research has shown that there was no difference in the amount of surfactant in infants with or without $\mathrm{CDH}$ [28] and that surfactant treatment during ECMO brought no improvement [13]. But despite the absence of supportive data and of controlled clinical trials to test the effect of exogenous surfactant, it is commonly used in most centers for babies born with $\mathrm{CDH}$ $[70,109]$. In summary, not only is there no proof that the administration of exogenous surfactant is beneficial, but it may even not be without risk. Complications of the administration of surfactant, such as a drop in arterial pressure, increased cerebral blood flow velocity or non responders, are infrequent [43].

\section{Calcium channel blockers}

Although calcium channel blockers are the first treatment for pulmonary hypertension, there are no reports of the use of these drugs in children with PPHT associated with $\mathrm{CDH}$. Nevertheless, these drugs are often used in combination with others, as drug combinations have proved more effective than a single drug alone, especially when a disease is resistant to treatment.

\section{NO}

The discovery and the use of NO in recent years is one of the major advances in the understanding of vascular regulation [32]. NO is a potent vasodilator produced by the endothelial cells of vessels, including pulmonary vessels. It improves oxygenation by decreasing PVR reducing pulmonary shunts. In human fetal lungs, the NO pathway is involved in angiogenesis, lung development, and vasorelaxation [53]. NO is known to modulate neutrophils and platelet adhesion, vascular smooth muscle proliferation, and capillary leak by reducing vascular permeability [79]. NO gives the vessels the ability to selfregulate contraction and relaxation (Fig. 4).

Inhaled NO is very efficient when treating pulmonary PPHT and respiratory failure in infants or newborn suffering from various diseases [10]. But it is not so in the case of children suffering from pulmonary hypertension due to $\mathrm{CDH}$, and the presence and activation of the NOS is still a subject of wide discussion [88, 100]. NO is nevertheless used against pulmonary hypertension in $\mathrm{CDH}$, in combination with mechanical ventilation/HFO, surfactant, and antihypertensive drugs. There has as yet been no randomized trial focused on the role of $\mathrm{NO}$ itself to assess its benefits and, worse, one publication reports a poorer outcome in children with $\mathrm{CDH}$ treated with $\mathrm{NO}$ [29].

Side effects of NO in high concentration are the potentialization of lung injury promoting oxidative stress, the inactivation of the surfactant production, the impairment of ciliary motility, and the increase in tissue inflammation and vascular permeability following plasma extravasation [79]. Inhalation of highly concentrated NO may convert it into a highly toxic peroxynitrite which may activate macrophages and impair surfactant production. The lungs of the newborn seem to be protected against birth-related oxidative stress by an increase in antioxidant activity [83]. Oxidative stress is responsible for dysregulation of the vascular tone, platelet aggregation, and increased vascular permeability. It contributes to apoptosis through changes in ionic transport, activation of enzymes and changes in the cystoskeleton [81].

Guanylate cyclase and cGMP-specific phosphodiesterase

Postnatal pulmonary vascular tone is influenced by various vasoconstrictors or vasodilators. Vasoconstrictors such as ET-1 or thromboxane $\mathrm{A}_{2}\left(\mathrm{TXA}_{2}\right)$ increase the vascular resistance [102], although ET-1 may also play a role in vasodilation in the newborn [75]. $\mathrm{TXA}_{2}$ and prostacyclin 
$\left(\mathrm{PGI}_{2}\right)$ are prostaglandins produced by the degradation of arachidonic acid by the cyclooxygenase enzyme (COX) [17]. Among vasodilators, NO [10, 53] activates soluble Guanylate cyclase (GC) found in vascular smooth muscle and $\mathrm{PGI}_{2}$ activates the smooth-muscle-membrane-bound enzyme adenylate cyclase (AC) [17], thereby increasing the level of cyclic $3^{\prime}-5^{\prime}$-guanylosine monophosphate (cGMP).

The cGMP dependent proteine kinase (PKG) activates calcium-dependent $\mathrm{K}^{+}$channels $\left(\mathrm{K}_{\mathrm{ca}}{ }^{2+}\right)$ through phosphorylation. The resulting hyperpolarization of the cell membrane inhibits the ion influx through voltage operated $\mathrm{Ca}^{2+}$ channels and causes vasodilation [82]. But cGMP is in turn rapidly inactivated by phosphodiesterase (PDE V) enzyme and is transformed into inactive $3^{\prime}-5^{\prime}$-guanylosine monophosphate (iGMP) which limits the vasodilatory response to NO [118] (Fig. 4). New management strategies in order to diminish persistent pulmonary hypertension at birth are based on the role of agents activating the GC, such as YC-1 (a benzyl indazole derivative) or inhibiting the PDE V, such as sildenafil [86].

\section{ECMO}

The use of ECMO is also controversial, and the choice of this interventional therapy is based largely on the belief of individual team leaders. This technique has become a standard treatment in specialized centers for infants born with a $\mathrm{CDH}$, even though one large randomized trial of ECMO reported in the literature reached conclusions which are not very precise and was unable to show its benefit over other techniques [107]. As usual, the main problem in comparing results is the difficulty to guarantee the integrity of the groups of children with $\mathrm{CDH}$ who receive a particular treatment, as the criteria applied to select these children are widely divergent [24]. Criteria for the use of ECMO vary widely from center to center, and the final decision is often reached only when an infant shows a clinical deterioration, a deterioration of blood gases, a mechanical ventilation with a peak inspiratory pressure higher than $25 \mathrm{mmHg}$, a compliance measurement less than $0.25 \mathrm{~mL} / \mathrm{cmH}_{2} \mathrm{O} / \mathrm{kg}$ and a tidal volume less than $3.5 \mathrm{~mL} / \mathrm{kg}$ [92]. Investigators have proposed different formulas based on blood gas components to predict the outcome of babies with $\mathrm{CDH}$ and to argue about the use of ECMO: the first is the alveolar-arterial oxygen gradient $\left(\mathrm{AadO}_{2}\right)$ calculated by the formula: $\mathrm{AadO}_{2}=\left[\left(713 \times \mathrm{FiO}_{2}\right)-\mathrm{PaCO}_{2} / 0.8\right]-\mathrm{PaO}_{2}$, $\mathrm{FiO}_{2}$ being the inspiratory fraction of $\mathrm{O}_{2}$ and $\mathrm{PaO}_{2}$ the arterial pressure of $\mathrm{O}_{2}$. The second is the ventilatory index (VI) calculated by the formula: $\mathrm{VI}=\left(\mathrm{RR} \times \mathrm{MAP} \times \mathrm{PaCO}_{2}\right)$, $\mathrm{RR}$ being the respiratory rate, MAP the median arterial pressure with a good prognosis when the index is less than 1000. The third is a modified VI (MVI) calculated by the formula $\mathrm{MVI}=\left(\mathrm{RR} \times \mathrm{PIP} \times \mathrm{PaCO}_{2}\right)$, PIP being the peak inspiratory pressure, and a result of less than 40 offers a good prognosis, a result of more than 80 a bad prognosis. Finally, the most commonly used calculation is the oxygenation index (OI) calculated by the formula $\mathrm{OI}=$ $\left(\mathrm{MAP} \times \mathrm{FiO}_{2} / \mathrm{PaO}_{2}\right)$, with initiation of ECMO for an OI of 40 or greater [57, 93]. Both venovenous and venoarterial techniques have been reported with equally effective results [56].
Fig. 4 Nitric oxide $(N O)$ can be synthesized endogenously by NO synthases $(N O S)$ or it can be provided by exogenous $\mathrm{NO}$ donors. NO diffuses towards the vascular smooth muscle and activates the soluble guanylate cyclase $(G C)$ found in vascular smooth muscle cells, thereby increasing the level of cyclic 3'5'-guanylosine monophosphate (cGMP). cGMP stimulates cGMP dependent protein kinases $(P K G)$ and is inactivated by type 5 phosphodiesterase (PDE V). Various pharmacological activators $(+)$ or inhibitors $(-)$ targeting the enzymes NOS, GC, PDE V, and PKG, are shown

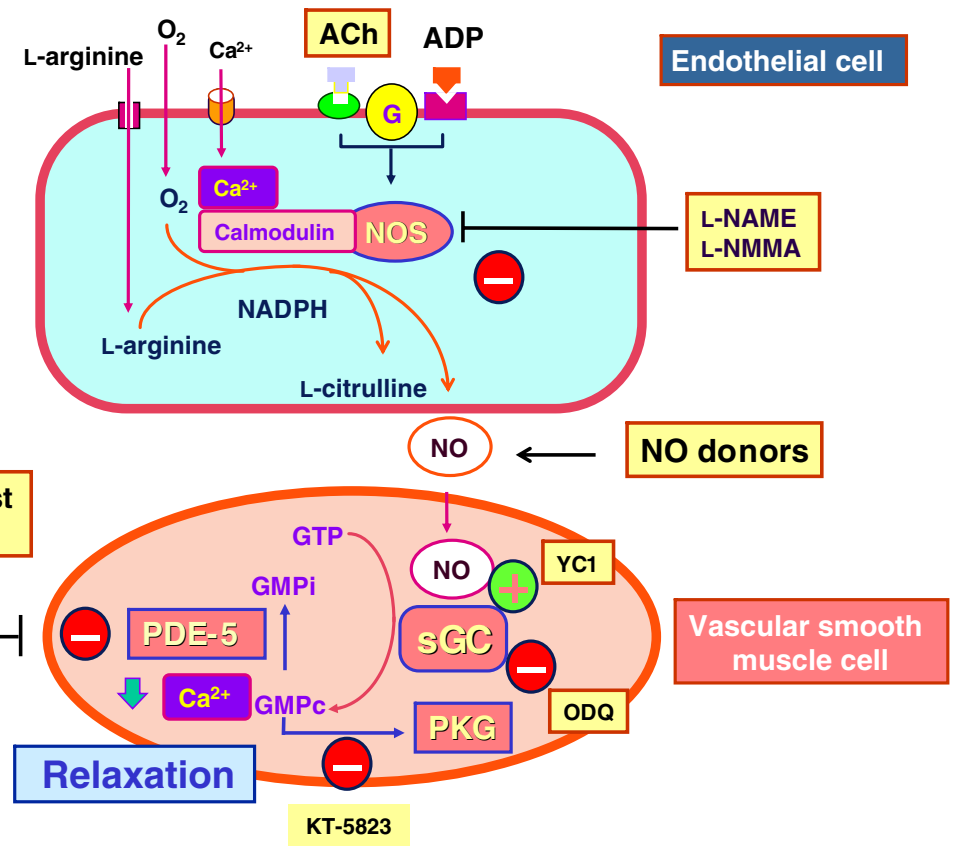




\section{$\mathrm{CDH}$ repair}

The rule in most centers is to delay surgery until the pulmonary hypertensive crisis in children born with $\mathrm{CDH}$ has been controlled. This period of adaptation at birth permits the stabilization of labile hemodynamic and pulmonary physiology as both lungs are affected by this pathology [42]. Nevertheless, studies tend to show that the timing of surgery makes no difference in the outcome of early and late repair groups [71]. The decision as to the optimum timing of surgery after birth must be discussed by a multidisciplinary team and must first and foremost take into account the stability of the child and its capacity to tolerate "gentle" ventilation with low peak pressure, a $\mathrm{FiO}_{2}$ lower than $50 \%$, a minimum of inhaled $\mathrm{NO}$, and good blood gas values [116]. Serial heart ultrasound examinations can help to assess blood flow shunts and pulmonary hypertension in comparison with systemic pressure. Nevertheless, the repair of a diaphragmatic defect will often worsen pulmonary compliance by reducing the elasticity of the chest wall and increasing the intraabdominal pressure.

Surgery usually begins with a subcostal incision giving access to the entire diaphragm. The spleen, the small intestine and the large intestine are generally herniated through the defect. When the herniated viscera have been reduced, the edges of the diaphragm should be recognized. This obliges the surgeon to dissect the posterior part of the diaphragm, which is often quite thin. Ideally, the diaphragm is closed after the reduction of the viscera with non absorbable interrupted sutures. Mattress sutures or pledgetted sutures can also be used. A laparoscopic approach in the skilled hands of a surgeon who is used to this particular surgical method is also possible and depends largely on the hemodynamic and the pulmonary stability of the child. A transthoracic approach to repair the defect is also described, especially for a $\mathrm{CDH}$ on the right side, and affords a nice view for a liver reduction [42].

Primary repair is not always possible. In the presence of a tension too excessive to permit primary repair, of a very large defect in a thin diaphragm or even an absent diaphragm, or of agenesis of the diaphragm, a prosthetic implant may be needed to close the defect. Technically, this implant must be attached all around in order to decrease the risk of recurrence of the hernia, and its attachment to the lateral part to the ribs and to the medial part of the thoracic cavity while safeguarding the passage of the esophagus and the aorta is challenging $[69,93]$. There is as yet no optimal patch material. The current materials are too rigid. This rigidity creates problems when the patient grows as the prosthetic implant does not adapt to the growth of the thoracic cavity, leading to thoracic deformation and scoliosis [69]. The development of bioengineered materials, also for other indications than $\mathrm{CDH}$, would be of great interest. Other technical solutions, such as a reversed latissimus dorsi muscle flap for the repair of recurrent $\mathrm{CDH}$, have also been described [98].

\section{Long-term follow-up}

Specialized multidisciplinary clinics are emerging in many centers to provide long-term follow-up for children born with $\mathrm{CDH}$. These children require the services of expert pediatricians who are trained in specific areas such as pulmonary, digestive, or musculoskeletal pathologies.

As children with a large defect and those with PPHT will often have multiple problems, a long follow-up is mandatory. The follow-up data for all children born with $\mathrm{CDH}$ shows that even those for whom recovery during the neonatal period is relatively easy may still have long-term problems. These problems can be recurrent herniation, delayed growth, chronic lung disease, feeding complications, gastroesophageal reflux, neurological impairment, deafness, and musculoskeletal deformations [49, 52, 105, $106,108]$. Factors such as parental socioeconomic status and education may contribute to making a long-term follow-up more difficult $[2,15]$.

Pulmonary problems concern obstructive or restrictive pulmonary function anomalies, or a combination of both. Persistent pulmonary hypoplasia produces ventilation perfusion mismatch and chronic lung disease with obstructive airway disease $[72,73]$. Children who suffer from these problems may need oxygen support for a long time and are discharged and sent home with the means to pursue this therapy. Chronic lung disease is defined as the need for ventilatory support, chronic bronchodilators, diuretics, or oxygen supplementation [16]. Bronchospasm, asthma, and wheezing are frequently reported in the literature [105]. Bronchial hyperreactivity to pharmacological products has also been reported [106]. A long-term study by Vanamo et al. [106] of young adults born with $\mathrm{CDH}$ or with a diaphragmatic eventration and treated between 1948 and 1980 showed that $83 \%$ of these patients considered themselves normal, that $12 \%$ had asthma and that $4 \%$ had recurrent respiratory tract infections. More recently, based on 100 consecutive CDH survivors, Muratore [73] showed that $16 \%$ of the patients remained oxygen-dependent for several months after their discharge and $43 \%$ diureticdependent for a maximum of 30 months after their discharge, and that viral bronchiolitis was strongly prevalent in children under 3 years of age. Kamata et al. [49] showed that morbidity due to recurrent pneumonia was the most prevalent (39\%) among $33 \mathrm{CDH}$ survivors who were followed for many years. Keller [52] reported in three patients born with $\mathrm{CDH}$ a persistent high pulmonary arterial pressure and a high PVR, measured by cardiac catheteriza- 
tion between the ages of three months and 12 years. Recently, Jaillard et al. [45] found after a 2-year follow-up that chronic lung disease was prevalent in $\mathrm{CDH}$ survivors, with a higher prevalence in children treated with ECMO or whose hernia had been repaired with a patch. Finally chest radiography may evidence hyperlucency, hyperinflation, persistent lung hypoplasia, decreased pulmonary vascularity, persistent lung opacities, mediastinal shift, or abnormal diaphragmatic profile [2].

Esophagogastric problems may present as esophageal dysmotility and gastroesophageal reflux (GER) and can occur in more than $50 \%$ of $\mathrm{CDH}$ children $[26,91]$. Failure to thrive due to these feeding-related problems is frequent in this population [73]. The variability in the data reported in various studies concerning the incidence of GER may depend on the method of diagnosis, for instance good clinical investigation, $\mathrm{pH}$ monitoring, milk-scan study and upper gastrointestinal contrast. Despite long discussions about the etiology of GER in CDH patients, its pathophysiology has not yet been elucidated and several anatomical hypotheses are proposed, such as kinking of the esophagus at the gastroesophageal junction, shortening of the abdominal esophagus portion, modification of the His angle or absence of the perihiatal diaphragm [2]. The presence of GER mandates a close follow-up of these patients, with appropriate medical treatment and even surgical treatment if necessary, in order to avoid sudden death, chronic pulmonary disease due to bronchoaspiration and failure to thrive $[15,104]$. Many other factors, such as chronic lung disease, the use of long-term oxygen, a long period of endotracheal intubation causing delayed swallowing, or the presence of a gastrostomy, contribute to eating difficulties and growth failure. Malrotation is associated with $\mathrm{CDH}$ and bowel obstruction is a well-known complication [64].

Deformities of the chest wall such as pectus excavatum and deformities of the spine, including scoliosis, are typical long-term problems which require a long-term follow-up. More than $40 \%$ of $\mathrm{CDH}$ survivors will suffer from these abnormalities [2]. These malformations are due mainly to the surgical repair with a patch in the case of a large diaphragmatic defect or with stitches fixed to the ribs when closure can be achieved without a patch. Whereas pectus excavatum and vertebral deformities are associated with large diaphragmatic defects, obstructive and/or restrictive pulmonary function anomalies are more often associated with scoliosis [69, 108].

Some studies show that children with $\mathrm{CDH}$ treated with ECMO may suffer from delayed neurological development and risk deafness [78]. These effects may be higher in children born with $\mathrm{CDH}$ and treated with ECMO than in children born without $\mathrm{CDH}$ and treated with ECMO [4, 65]. Other studies find that whether or not ECMO is used makes no difference in the neurological development of children born with $\mathrm{CDH}[31,46,92]$. Because ECMO has been associated with neurological complications due to the use of anticoagulant treatment, it is usually reserved for very sick babies with high pulmonary hypertension and a high risk of hypoxic and ischemic brain injuries, characteristics which in themselves entail a prognosis of long-term morbidity. As for sensorineuronal hearing loss, it is a risk for babies born with $\mathrm{CDH}$ because of the use of ototoxic medications such as diuretics, muscle relaxants, and antibiotics [31]. Prolonged ventilation is also a factor of risk [112].

Acknowledgments The authors are grateful to Mrs. Anne-Marie Wagnière for reviewing the English manuscript and to Dr Sarah Bouchard, Sainte-Justine Hospital, Montreal, Québec, Canada for her constructive advice.

The authors have no financial relationship with the organization that sponsored the research.

\section{References}

1. Accurso FJ, Alpert B, Wilkening RB, Petersen RG, Meschia G (1986) Time-dependent course of fetal pulmonary blood flow to an increase in fetal oxygen tension. Respir Physiol 63:43-52. doi:10.1016/0034-5687(86)90029-0

2. Bagolan P, Morini F (2007) Long-term follow-up of infants with congenital diaphragmatic hernia. Semin Pediatr Surg 16:134144. doi:10.1053/j.sempedsurg.2007.01.009

3. Babiuk RP, Zhang W, Clugston R, Allan DW, Greer JJ (2003) Embryological origins and development of the rat diaphragm. J Comp Neurol 455:477-487. doi:10.1002/cne.10503

4. Bernbaum J, Schwartz IP, Gerdes M, D'Agostino JA, Coburn CE, Polin RA (1995) Survivors of extracorporeal membrane oxygenation at 1 year of age: the relationship of primary diagnosis with health and neurodevelopmental sequelae. Pediatrics 96:907-913

5. Bhuta T, Clark RH, Henderson-Smart DJ (2001) Rescue high frequency oscillatory ventilation vs conventionnal ventilation for infants with severe pulmonary dysfunction born at near term. Cochrane Database Syst Rev 1:CDOO2974

6. Bohn D (2002) Congenital diaphragmatic hernia. Am J Respir Crit Care Med 166:911-915. doi:10.1164/rccm.200204-304CC

7. Boix-Ochoa J, Peguero G, Seijo G, Natal A, Canals J (1974) Acid-base balance and blood gases in prognosis and therapy of congenital diaphragmatic hernia. J Pediatr Surg 9:49-57. doi:10.1016/0022-3468(74)90009-8

8. Bouchard S, Johnson P, Flake A (2002) The EXIT procedure: experience and outcome in 31 cases. J Pediatr Surg 37:418-426. doi:10.1053/jpsu.2002.30839

9. Calkovská A, Javorka K, Petrásková M, Laucoková-Misíková I, Drgová A, Gál M (1997) Changes in mechanisms of breathing during high-frequency jet ventilation: what is the cause? Physiol Res 46:271-278

10. Clark RH, Kueser TJ, Walker MW (2000) Low-dose nitric oxide therapy for persistent pulmonary hypertension of the newborn. Clinical Inhaled Nitric Oxide Research Group. N Engl J Med 342:469-474. doi:10.1056/NEJM200002173420704

11. Cloutier M, Seaborn T, Piedboeuf B, Bratu I, Flageole H, Laberge JM (2005) Effect of temporary tracheal occlusion on the endothelin system in experimental cases of diaphragmatic hernia. Exp Lung Res 31:391-404. doi:10.1080/019021490927079 
12. Clugston RD, Greer JJ (2007) Diaphragm development and congenital diaphragmatic hernia. Semin Pediatr Surg 16:94-100. doi:10.1053/j.sempedsurg.2007.01.004

13. Cogo PE, Zimmermann LJ, Rosso F (2002) Surfactant synthesis and kinetics in infants with congenital diaphragmatic hernia. Am J Respir Crit Care Med 166:154-158. doi:10.1164/ recm. 2108028

14. Coleman BG, Adzick NS, Crombleholme TM (2002) Fetal therapy: state of the art. J Ultrasound Med 21:1257-1288

15. Crankson SJ, Al Jadaan SA, Namshan MA, Al-Rabeeah AA, Oda O (2006) The immediate and long-term outcomes of newborn with congenital diaphragmatic hernia. Pediatr Surg Int 22:335-340. doi:10.1007/s00383-006-1643-6

16. D'agostino JA, Bernbaum JC, Gerdes M (1995) Outcome for infants with congenital diaphragmatic hernia requiring extracorporeal membrane oxygenation: the first year. J Pediatr Surg 30:10-15. doi:10.1016/0022-3468(95)90598-7

17. Davidson D (1998) Pulmonary hemodynamics at birth: effect of acute cyclooxygenase inhibition in lambs. J Appl Physiol 64:1676-1682

18. de Mello DE, Reid LM (2000) Embryonic and early fetal development of human lung vasculature and its functional implications. Pediatr Dev Pathol 3:439-449. doi:10.1007/ s100240010090

19. Deprest J, Jani J, Cannie M (2006) Prenatal intervention for isolated congenital diaphragmatic hernia. Curr Opin Obstet Gynecol 18:355-367. doi:10.1097/01.gco.0000193000.12416.80

20. Deprest J, Jani J, Lewi L (2006) Fetoscopic surgery: encouraged by clinical experience and boosted by instrument innovation. Semin Fetal Neonatal Med 11:398-412. doi:10.1016/j. siny.2006.09.003

21. Deprest J, Gratacos E, Nicolaides KH (2004) Fetoscopic tracheal occlusion (FETO) for severe congenital diaphragmatic hernia: evolution of a technique and preliminary results. Ultrasound Gynecol 24:121-126. doi:10.1002/uog.1711

22. Desfrère L, Jarreau PH, Dommergues M (2000) Impact of delayed repair and elective high-frequency oscillatory ventilation on survival of antenatally diagnosed congenital diaphragmatic hernia: first application of these strategies in the more severe subgroup of antenatally diagnosed newborns. Intensive Care Med 26:934-941. doi:10.1007/s001340051284

23. DiFiore JW, Fauza DO, Slavin R, Wilson JM (1995) Experimental fetal tracheal ligation and congenital diaphragmatic hernia: a pulmonary vascular morphometric analysis. J Pediatr Surg 30:917-923. doi:10.1016/0022-3468(95)90313-5

24. Elbourne D, Field D, Mugford M (2002) Extracorporeal membrane oxygenation for severe respiratory failure in newborn infants. Cochrane Database Syst Rev 1:CDOO1340

25. Elhalaby EA, Abo Sikeena MH (2002) Delayed presentation of congenital diaphragmatic hernia. Pediatr Surg Int 18:480-485. doi:10.1007/s00383-002-0743-1

26. Fasching G, Huber A, Uray E, Sorantin E, Lindbichler F, Mayr J (2000) Gastroesophageal reflux and diaphragmatic motility after repair of congenital diaphragmatic hernia. Eur J Pediatr Surg 10:360-364

27. Fauza DO, Wilson JM (1994) Congenital diaphragmatic hernia and associated anomalies: their incidence, identification, and impact on prognosis. J Pediatr Surg 29:1113-1117. doi:10.1016/ 0022-3468(94)90290-9

28. Finer NN, Tierney A, Etches PC, Peliowski A, Ainsworth W (1998) Congenital diaphragmatic hernia: developing a protocolized approach. J Pediatr Surg 33:1331-1337. doi:10.1016/ S0022-3468(98)90001-X

29. Finer NN, Barrington KJ (2001) Nitric oxide for respiratory failure in infants born at a near term. Cochrane Database Syst Rev 4:CDOO399
30. Flake A, Crombleholme T, Johnson M, Howell LJ, Adzick NS (2000) Treatment of severe congenital diaphragmatic hernia by fetal tracheal occlusion: clinical experience with fifteen cases. Am J Obstet Gynecol 183:1059-1066. doi:10.1067/ mob.2000.108871

31. Fligor BJ, Neault MW, Mullen CH, Feldman HA, Jones DT (2005) Factors associated with sensorineural hearing loss among survivors of extracorporeal membrane oxygenation therapy. Pediatrics 115:1519-1528. doi:10.1542/peds.2004-0247

32. Furchgott RF, Zawadzki JV (1980) The obligatory role of endothelial cells in the relaxation of arterial smooth muscle by acetylcholine. Nature 288:373-376. doi:10.1038/288373a0

33. Garne E, Haeusler M, Barisic I, Gjergja R, Stoll C, Clementi M (2002) Euroscan Study Group. Congenital diaphragmatic hernia: evaluation of prenatal diagnosis in 20 European regions. Ultrasound Obstet Gynecol 19:329-333. doi:10.1046/j.14690705.2002.00635.x

34. Geggel RL, Murphy JD, Langleben D, Crone RK, Vacanti JP, Reid LM (1985) Congenital diaphragmatic hernia: arterial structural changes and persistent pulmonary hypertension after surgical repair. J Pediatr 107:457-464. doi:10.1016/S0022-3476 (85)80534-5

35. Glick PL, Stannard VA, Leach CL (1992) Pathophysiology of congenital diaphragmatic hernia II: the fetal lamb CD model is surfactant deficient. J Pediatr Surg 27:382-387. doi:10.1016/ 0022-3468(92)90865-5

36. Greer JJ, Cote D, Allan DW (2000) Structure of the primordial diaphragm and defects associated with nitrofen-induced CDH. J Appl Physiol 89:2123-2129

37. Hara A, Chapin CJ, Ertsey R, Kitterman JA (2005) Changes in fetal lung distension alter expression of vascular endothelial growth factor and its isoforms in developing rat lung. Pediatr Res 58:30-37. doi:10.1203/01.PDR.0000163614.20031.C5

38. Harrison MR, Adzick NS, Longaker MT (1990) Successful repair in utero of fetal diaphragmatic hernia after removal of herniated viscera from the left thorax. N Engl J Med 322:15821584

39. Harrison MR, Adzick NS, Bullard KM (1997) Correction of congenital diaphragmatic hernia in utero VII: a prospective trial. J Pediatr Surg 32:1637-1642. doi:10.1016/S0022-3468(97) 90472-3

40. Harrison MR, Mychaliska GB, Albanese CT (1998) Correction of congenital diaphragmatic hernia in utero IX: fetuses with poor prognosis can be saved by fetoscopic temporary tracheal occlusion. J Pediatr Surg 33:1017-1022. doi:10.1016/S00223468(98)90524-3

41. Harrison MR, Keller RL, Hawgood SB (2003) A randomized trial of fetal endoscopic tracheal occlusion for severe fetal congenital diaphragmatic hernia. N Engl J Med 349:19161924. doi:10.1056/NEJMoa035005

42. Harting MT, Lally KP (2007) Surgical management of neonates with congenital diaphragmatic hernia. Semin Pediatr Surg 16:109-114. doi:10.1053/j.sempedsurg.2007.01.007

43. Hentschel R, Joerch G (2002) Acute side effects of surfactant treatment. J Perinat Med 30:143-148. doi:10.1515/ JPM.2002.018

44. Inselman LS, Mellins RB (1981) Growth and development of the lung. J Pediatr 98:1-15. doi:10.1016/S0022-3476(81)80524-0

45. Jaillard SM, Pierrat V, Dubois A (2003) Outcome at 2 years of infants with congenital diaphragmatic hernia: a population-based study. Ann Thorac Surg 75:250-256. doi:10.1016/S0003-4975 (02)04278-9

46. Jaillard S, Pierrat V, Truffert P (2000) Two years' follow-up of newborn infants after extracorporeal membrane oxygenation (ECMO). Eur J Cardiothorac Surg 18:328-333. doi:10.1016/ S1010-7940(00)00514-5 
47. Javid PJ, Jaksic T, Skarsgard ED, Lee S (2004) Canadian neonatal network. Survival rate in congenital diaphragmatic hernia: the experience of the Canadian neonatal network. J Pediatr Surg 39:657-660. doi:10.1016/j.jpedsurg.2004.01.022

48. Kaiser JR, Rosenfeld CR (1999) A population-based study of congenital diaphragmatic hernia: impact of associated anomalies and preoperative blood gases on survival. J Pediatr Surg 34:1196-1202. doi:10.1016/S0022-3468(99)90151-3

49. Kamata S, Usui N, Kamiyama M (2005) Long-term follow-up of patients with high-risk congenital diaphragmatic hernia. J Pediatr Surg 40:1833-1838. doi:10.1016/j.jpedsurg.2005.08.022

50. Kanai M, Kitano Y, von Allmen D, Davies P, Adzick NS, Flake AW (2001) Fetal tracheal occlusion in the rat model of nitrofeninduced congenital diaphragmatic hernia: tracheal occlusion reverses the arterial structural abnormality. J Pediatr Surg 36:839-845. doi:10.1053/jpsu.2001.23950

51. Karamanoukian HL, Glick PL, Wilcox DT (1995) Pathophysiology of congenital diaphragmatic hernia XI: anatomic and biochemical characterization of the heart in the fetal lamb $\mathrm{CDH}$ model. J Pediatr Surg 30:925-929. doi:10.1016/0022-3468(95) 90314-3

52. Keller RL, Moore P, Teitel D, Hawgood S, McQuitty J, Fineman JR (2006) Abnormal vascular tone in infants and children with lung hypoplasia: findings from cardiac catheterization and the response to chronic therapy. Pediatr Crit Care Med 7:589-594. doi:10.1097/01.PCC.0000244401.53189.CB

53. Kinsella JP, Abman S (2007) Inhaled nitric oxide in the premature newborn. J Pediatr 151:10-15. doi:10.1016/j. jpeds.2007.02.010

54. Kitano Y, Kanai M, Davies P (2001) Lung growth induced by prenatal tracheal occlusion and modifying factors: a study in the rat model of congenital diaphragmatic hernia. J Pediatr Surg 36:251-259. doi:10.1053/jpsu.2001.20683

55. Kluth D, Keijzer R, Hertl M, Tibboel D (1996) Embryology of congenital diaphragmatic hernia. Semin Pediatr Surg 4:224-233

56. Kugelman A, Gangitano E, Pincros J, Tantivit P, Taschuk R, Durand M (2003) Venovenous versus venoarterial extracorporeal membrane oxygenation in congenital diaphragmatic hernia. J Pediatr Surg 38:1131-1136. doi:10.1016/S0022-3468(03)002562

57. Lally KP (2002) Congenital diaphragmatic hernia. Curr Opin Pediatr 14:486-490. doi:10.1097/00008480-200208000-00022

58. Langham MR, Kays DW, Ledbetter DJ, Frentzen B, Sanford LL, Richards DS (1996) Congenital diaphragmatic hernia: epidemiology and outcome. Clin Perinatol 23:671-688

59. Laudy JA, Van Gucht M, Van Dooren MF, Wladimiroff JW, Tibboel D (2003) Congenital diaphragmatic hernia: an evaluation of the prognostic value of the lung-to-head ratio and other prenatal parameters. Prenat Diagn 23:634-639. doi:10.1002/ pd.654

60. Lipshutz GS, Albanese CT, Feldstein VA (1997) Prospective analysis of lung-to-head ratio predicts survival for patients with prenatally diagnosed congenital diaphragmatic hernia. J Pediatr Surg 32:1634-1636. doi:10.1016/S0022-3468(97)90471-1

61. Logan JW, Cotton CM, Goldberg RN, Clark RH (2007) Mechanical ventilation strategies in the management of congenital diaphragmatic hernia. Semin Pediatr Surg 16:115-125. doi:10.1053/j.sempedsurg.2007.01.006

62. Lotze A, Knight GR, Anderson KD (1994) Surfactant (beractant) therapy for infant with congenital diaphragmatic hernia on ECMO: evidence of persistent surfactant deficiency. J Pediatr Surg 29:407-412. doi:10.1016/0022-3468(94)90580-0

63. Luks FI, Wild YK, Piasecki GJ, de Paepe ME (2000) Short-term tracheal occlusion corrects pulmonary vascular anomalies in the fetal lamb with diaphragmatic hernia. Surgery 128:266-272. doi: $10.1067 / \mathrm{msy} .2000 .107373$
64. Lund DP, Mitchell J, Kharasch V, Quigley S, Kuehn M, Wilson JM (1994) Congenital diaphragmatic hernia: the hidden morbidity. J Pediatr Surg 29:258-262. doi:10.1016/0022-3468(94) 90294-1

65. McGahren ED, Mallik K, Rodgers BM (1997) Neurological outcome is diminished in survivors of congenital diaphragmatic hernia requiring extracorporeal membrane oxygenation. J Pediatr Surg 32:1216-1220. doi:10.1016/S0022-3468(97) 90685-0

66. Meyer KC, Zimmermann JJ (2002) Inflammation and surfactant. Paediatr Respir Rev 3:308-314. doi:10.1016/S1043-6618(02) 00212-8

67. Mohseni-Bod H, Bohn D (2007) Pulmonary hypertension in congenital diaphragmatic hernia. Semin Pediatr Surg 16:126133. doi:10.1053/j.sempedsurg.2007.01.008

68. Morin FC III, Stenmark KR (1995) Persistent pulmonary hypertension of the newborn. Am J Respir Crit Care Med 151:2010-2035

69. Moss RL, Chen CM, Harrison MR (2001) Prosthetic patch durability in congenital diaphragmatic hernia: a long-term follow-up study. J Pediatr Surg 36:152-154. doi:10.1053/ jpsu.2001.20037

70. Moya FR, Thomas VL, Romaguera J (1995) Fetal lung maturation in congenital diaphragmatic hernia. Am J Obstet Gynecol 173:1401-1405. doi:10.1016/0002-9378(95)90624-X

71. Moyer V, Moya F, Tibboel R, Losty P, Nagaya M, Lally KP (2002) Late versus early surgical correction for congenital diaphragmatic hernia in newborn infants. Cochrane Database Syst Rev 3:CD001695

72. Muratore CS, Kharasch V, Lund DP (2001) Pulmonary morbidity in 100 survivors of congenital diaphragmatic hernia monitored in a multidisciplinary clinic. J Pediatr Surg 30:133-140. doi:10.1053/jpsu.2001.20031

73. Muratore CS, Utter S, Jaksic T, Lund DP, Wilson JM (2001) Nutritional morbidity in survivors of congenital diaphragmatic hernia. J Pediatr Surg 36:1171-1176. doi:10.1053/ jpsu.2001.25746

74. Nose K, Kamata S, Sawai T (2000) Airway anomalies in patients with congenital diaphragmatic hernia. J Pediatr Surg 35:15621565. doi:10.1053/jpsu.2000.18310

75. Ovadia B, Bekker JM, Fitzgerald R, Kon A, Thelitz S, Johengen MJ, Hendricks Munoz K, Gerrets R, Black SM, Fineman JR (2002) Nitric oxide endothelin 1 interactions after ductal constriction in fetal lambs. Am J Physiol Heart Circ Physiol 284:H480-H490

76. Pringle KC, Turner JW, Schofield JC, Soper RT (1984) Creation and repair of diaphragmatic hernia in the fetal lamb: lung development and morphology. J Pediatr Surg 19:131-140. doi:10.1016/S0022-3468(84)80432-7

77. Quintero RA, Morales WJ, Bornick PW (2000) Tracheal side effects of endoscopic balloon tracheal occlusion in the fetal lamb model. Eur J Obstet Gynecol Reprod Biol 92:119-126. doi:10.1016/S0301-2115(00)00435-8

78. Rasheed A, Tindall S, Cueny DL, Klein MD, Delaney-Black V (2001) Neurodevelopmental outcome after congenital diaphragmatic hernia: extracorporeal membrane oxygenation before and after surgery. J Pediatr Surg 36:539-544. doi:10.1053/ jpsu.2001.22278

79. Ricciardolo FLM, Sterk PJ, Gaston B, Folkerts G (2004) Nitric oxide in health and disease of the respiratory system. Physiol Rev 84:731-765. doi:10.1152/physrev.00034.2003

80. Ruano R, Aubry MC, Barthe B, Mitanchez D, Dumez Y, Benachi A (2006) Quantitative analysis of fetal pulmonary vasculature by 3-dimensional power Doppler ultrasonography in isolated congenital diaphragmatic hernia. Am J Obstet Gynecol 195:1720-1728. doi:10.1016/j.ajog.2006.05.010 
81. Sanders KA, Huecksteadt T, Xu P, Sturrock AB, Hoidal JR (1999) Regulation of oxidant production in acute lung injury. Chest 116(Supp1 1):56S-61S. doi:10.1378/chest.116. suppl_1.56S

82. Saqueton CB, Miller RB, Porter VA, Milla CE, Cornfield DN (1996) NO causes perinatal pulmonary vasodilation though $\mathrm{K}^{+}$ channel activation and intracellular $\mathrm{Ca}^{2+}$ release. Am J Physiol 276:925-932

83. Saugstad OD (1990) Oxygen toxicity in the neonatal period. Acta Paediatr Scand 79:881-892. doi:10.1111/j.1651-2227.1990. tb11348.x

84. Sbragia L, Paek B, Filly R (2000) Congenital diaphragmatic hernia without herniation of the liver: Does the lung-to-head ratio predict survival? J Ultrasound Med 19:845-848

85. Schachtner SK, Wang Y, Scott Baldwin H (2000) Qualitative and quantitative analysis of embryonic pulmonary vessel formation. Am J Respir Cell Mol Biol 22:157-165

86. Noori S, Friedlich P, Wong P, Garingo A, Seri I (2007) Cardiovascular effects of sildenafil in neonates and infants with congenital diaphragmatic hernia and pulmonary hypertension. Neonatology 91:92-100. doi:10.1159/000097125

87. Shaffer TH, Wolfson MR (1996) Liquid ventilation: an alternative ventilation strategy for management of neonatal respiratory distress. Eur J Pediatr 155(Suppl 2):S30-S34. doi:10.1007/ BF01958078

88. Shehata SM, Sharma HS, Mooi WJ, Tibboel D (2006) Pulmonary hypertension in human newborns with congenital diaphragmatic hernia is associated with decreased vascular expression of nitric-oxide synthase. Cell Biochem Biophys 44:147-155. doi:10.1385/CBB:44:1:147

89. Skari H, Bjornland K, Haugen G, Egeland T, Emblem R (2000) Congenital diaphragmatic hernia: a meta-analysis of mortality factors. J Pediatr Surg 35:1187-1197. doi:10.1053/ jpsu.2000.8725

90. Stege G, Fenton A, Jaffray B (2003) Nihilism in the 1990s: the true mortality of congenital diaphragmatic hernia. Pediatrics 112:532-535. doi:10.1542/peds.112.3.532

91. Stolar CJ, Levy JP, Dillon PW, Reyes C, Belamarich P, Berdon WE (1990) Anatomic and functional abnormalities of the esophagus in infants surviving congenital diaphragmatic hernia. Am J Surg 159:204-207. doi:10.1016/S0002-9610(05) 80261-2

92. Stolar CJ, Crisafi MA, Driscoll YT (1995) Neurocognitive outcome for neonates treated with extracorporeal membrane oxygenation: are infants with congenital diaphragmatic hernia different? J Pediatr Surg 30:366-371. doi:10.1016/0022-3468 (95) $90591-X$

93. Stolar CJH, Dillon PW (2006) Congenital diaphragmatic hernia and eventration. In: Grosfeld JL, O’Neill Jr JA, Fonkalsrud EW, Coran AG (eds) Pediatric surgery. 6th edn. Elsevier, Philadelphia, pp 931-954

94. Suda K, Bigras JL, Bohn D, Hornberger LK, McCrindle BW (2000) Echocardiographic predictors of outcome in newborns with congenital diaphragmatic hernia. Pediatrics 105:1106-1109. doi:10.1542/peds.105.5.1106

95. Suen HC, Bloch KD, Donahoe PK (1994) Antenatal glucocorticoid corrects pulmonary immaturity in experimental induced congenital diaphragmatic hernia in rats. Pediatr Res 35:523-529. doi:10.1203/00006450-199405000-00002

96. Sweed Y, Puri P (1993) Congenital diaphragmatic hernia: influence of associated malformations on survival. Arch Dis Child 69:68-70

97. Swietlinski J, Swist-Szulik K, Maruniak-Cheduck I, Pyrkosz A (2002) Spondylothoracic dysostosis associated with diaphragmatic hernia and camptodactyly. Genet Couns 13:309317
98. Sydorak RM, Hoffman W, Lee H (2003) Reversed latissimus dorsi muscle flap for repair of recurrent congenital diaphragmatic hernia. J Pediatr Surg 38:296-300. doi:10.1053/jpsu.2003.50097

99. Taira Y, Yamataka T, Miyazaki IE, Puri P (1998) Comparison of the pulmonary vasculature in newborns and stillborns with congenital diaphragmatic hernia. Pediatr Surg Int 14:30-35. doi:10.1007/s003830050429

100. Thébaud B, Mercier JC, Dinh-Xuan AT (1998) Congenital diaphragmatic hernia: a cause of persistent pulmonary hypertension of the newborn which lacks an effective therapy. Biol Neonate 74:323-336. doi:10.1159/000014050

101. Thébaud B, Tibboel D, Rambaud C (1999) Vitamin A decreases the incidence and severity of nitrophen-induced congenital diaphragmatic hernia in rats. Am J Physiol 277:L423-L429

102. Thebaud B, de Lagausie P, Forgues D, Aigrain Y, Mercier JC, Dinh-Xuan AT (2000) ET (A)-receptor blockade and ET (B)receptor stimulation in experimental congenital diaphragmatic hernia. Am J Physiol Lung Cell Mol Physiol 278(5):L923L932

103. Thébaud B, Barlier-Mur AM, Chailley-Heu B (2001) Restoring effects of vitamin A on surfactant synthesis in nitrofen-induced congenital diaphragmatic hernia in rats. Am J Respir Crit Care Med 164:1083-1089

104. The Congenital Diaphragmatic Hernia Study Group (2003) Bilateral congenital diaphragmatic hernia. J Pediatr Surg 38:522-524. doi:10.1053/jpsu.2003.50092

105. Trachsel D, Selvadurai H, Bohn D, Langer JC, Coates AL (2005) Long-term pulmonary morbidity in survivors of congenital diaphragmatic hernia. Pediatr Pulmonol 39:433-439. doi:10.1002/ppul.20193

106. Vanamo K, Rintala R, Sovijärvi A (1996) Long-term pulmonary sequelae in survivors of congenital diaphragmatic defects. J Pediatr Surg 31:1096-1099. doi:10.1016/S0022-3468(96) 90095-0

107. UK Collaborative ECMO Trial Group (1996) UK Collaborative randomised trial of neonatal extracorporeal membrane oxygenation. Lancet 348:75-82. doi:10.1016/S0140-6736(96)04100-1

108. Vanamo K, Peltonen J, Rintala R, Lindahl H, Jääskeläinen J, Louhimo I (1996) Chest wall and spinal deformities in adults with congenital diaphragmatic defects. J Pediatr Surg 31:851854. doi:10.1016/S0022-3468(96)90152-9

109. van Meurs K (2004) Is surfactant therapy beneficial in the treatment of the term newborn infant with $\mathrm{CDH}$ ? J Pediatr 145:312-316. doi:10.1016/j.jpeds.2004.04.056

110. Veldhuizen RAW, Slutsky AS, Joseph M, Mc Caig L (2001) Effects of mechanical ventilation of isolated mouse lungs on surfactant and inflammatory cytokines. Eur Respir J 17:488-494. doi:10.1183/09031936.01.17304880

111. Wallace MJ, Thiel AM, Lines AM, Polglase GR, Sozo F, Hooper SB (2006) Role of platelet-derived growth factor-B, endothelial growth factor, insulin-like growth factor-II, mitogen-activated protein kinase and transforming growth factor-beta 1 in expansion-induced lung growth in fetal sheep. Reprod Fertil Dev 18:655-665. doi:10.1071/RD05163

112. Walton JP, Hendricks-Munoz K (1991) Profile and stability of sensorineural hearing loss in persistent pulmonary hypertension of the newborn. J Speech Hear Res 34:1362-1370

113. Wilcox DT, Glick PL, Karamanoukian HL, Holm BA (1997) Contributions by individual lungs to the surfactant status in congenital diaphragmatic hernia. Pediatr Res 41:686-691. doi:10.1203/00006450-199705000-00014

114. Wilson JM, DiFiore JW, Peters CA (1993) Experimental fetal tracheal ligation prevents the pulmonary hypoplasia associated with fetal nephrectomy: possible application for congenital diaphragmatic hernia. J Pediatr Surg 28:1433-1439. doi:10.1016/0022-3468(93)90426-L 
115. Wolfson MR, Shaffer TH (1999) Liquid assisted ventilation update. Eur J Pediatr 158(Suppl 1):S27-S31. doi:10.1007/ PL00014317

116. Wung JT, Sahni R, Moffitt ST, Lipsitz E, Stolar CJ (1995) Congenital diaphragmatic hernia: survival treated with very delayed surgery, spontaneous respiration and no chest tube. J Pediatr Surg 30:406-409. doi:10.1016/0022-3468(95)90042-X

117. Yamataka T, Puri P (1997) Pulmonary artery structural changes in pulmonary hypertension complicating congenital diaphrag- matic hernia. J Pediatr Surg 32:387-390. doi:10.1016/S00223468(97)90587-X

118. Ziegler JW, Ivy DD, Fox JJ, Kinsella JP, Clarke WR, Abman SH (1995) Dipyridamole, a cGMP phosphodiesterase inhibitor, causes pulmonary vasodilation in the ovine fetus. Am J Physiol Heart Circ Physiol 269:H473-H479

119. Zimmermann LJ, Janssen DJ, Tibboel D, Hamvas A, Carnielli VP (2005) Surfactant metabolism in the neonate. Biol Neonate 87:296-307. doi:10.1159/000084877 